\title{
Assessment of respiratory function in patients with chronic obstructive airways disease
}

\author{
I P F MUNGALL AND R HAINSWORTH
}

From the Killingbeck Hospital, Leeds, and the Department of Cardiovascular Studies, University of Leeds, Leeds LS2 9JT, UK

ABSTRACT The reproducibility of some respiratory function tests and a simple self-paced walking test were assessed in 13 patients with stable chronic obstructive airways disease by making observations on six occasions at two to three weekly intervals. The coefficients of variation of the various tests were as follows: forced expiratory volume in one second, $\pm 14.8 \%$; forced vital capacity, $\pm 11 \cdot 1 \%$; transfer factor (single breath carbon monoxide), $\pm 15 \%$; total lung capacity, $\pm 8.8 \%$ by helium dilution and $\pm 8.3 \%$ by body plethysmography; increase in heart rate and minute ventilation for an increase in oxygen uptake of $0.51 \mathrm{~min}^{-1}, \pm 19.4 \%$ and $\pm 16.3 \%$; distance covered in a 12 -minute walking test, $\pm 8.2 \%$. The 12 -minute distance increased significantly over the first three studies. The considerable variations in the result of these tests in subjects with apparently stable clinical states and without changes in treatment should be considered when assessing the results of changes in treatment.

Although there have been many long-term studies of respiratory function in patients with chronic obstructive airways disease (Bates et al, 1971), there is little information on the variability of the results of respiratory function tests over a short term when the clinical condition is stable. This information is necessary to allow the evaluation of the effects of changes in treatment. In the present study we have assessed the reproducibility of the results of some commonly used respiratory function tests and of the 12-minute walking test described by McGavin et al (1976). We have also studied the relationship of the results of the walking test to the results of the other tests.

\section{Methods and subjects}

Thirteen patients were studied who had chronic bronchitis as defined by the Medical Research Council Working Party (1965) or radiological emphysema as described by Laws and Heard (1962). All patients were men with a mean age of 55.4 years (range 47-64), and none had evidence of ischaemic heart disease or other serious illness. None had reversible bronchoconstriction-that is, forced expiratory volume in one second $\left(\mathrm{FEV}_{1}\right)$ increased by less than $20 \%$ in response to inhaled salbutamol. Patients attended the respiratory function laboratory as outpatients on six occasions at two to three weekly intervals. They were asked not to attend during exacerbations of their illness. Although no formal attempt was made to randomise the time of year for entry to the trial, in practice one new patient started approximately each month. Subjects were advised not to smoke and to continue their usual medication. Smoking habits and drug treatment were recorded to ensure that there were no changes during the trial. At each attendance the following tests were done, in the same order: (a) "standard tests of respiratory function," (b) 12-minute walking test, and (c) exercise studies. Subjects were allowed at least 10 minutes rest between each group of tests. The tests were performed by the same two observers throughout, using the same equipment.

\section{Standard respiratory function tests}

Measurements were made, by spirometry, of FEV and forced vital capacity (FVC). Transfer factor (TLCO) was determined in triplicate, by the single breath carbon monoxide method. Total lung capacity (TLC) was determined, in triplicate, both by helium dilution and by body plethysmography.

\section{Twelve-minute walking test}

This was performed in a covered hospital corridor according to the method of McGavin et al (1976). 


\section{Exercise tests}

A three-lead electrocardiogram was obtained to trigger a digital cardiotachometer (SE Laboratories). Expired gas was collected, using a threeway respiratory valve, in a 1201 spirometer (Collins) and minute ventilation and oxygen uptake were calculated. Measurements were made during a five-minute rest period and during the fifth minute of each of two five-minute exercise periods. The subjects exercised on a treadmill (Quinton Instruments), and the rates and gradients were selected for each patient to be well within his capabilities. The results of the exercise test were analysed by plotting, for each subject at each assessment, the relationships between minute ventilation and oxygen uptake, and heart rate and oxygen uptake. These relationships were analysed by determining the changes in minute ventilation and heart rate when oxygen uptake increased from $0.51 \mathrm{~min}^{-1}$ to $1.01 \mathrm{~min}^{-1}$ (Cotes, 1972).

\section{Results}

STANDARD RESPIRATORY FUNCTION TESTS

The mean results and standard deviations of $\mathrm{FEV}_{1}$, FVC, TLCO, and TLC, by both helium dilution and body plethysmography, from each patient, are listed in the table. The mean coefficients of variation of the results from all subjects were as follows: $\mathrm{FEV}_{1} \pm 14.8 \%$ (range 4.8-50), FVC \pm $11 \cdot 1 \%(4 \cdot 3-25 \cdot 9)$, TLCO $\pm 15 \%(6 \cdot 5-28 \cdot 4)$, TLC by helium dilution $\pm 8.8 \%(4-28 \cdot 8)$, and TLC by body plethysmograph $\pm 8 \cdot 3 \%(1 \cdot 6-20 \cdot 2)$.

To determine whether there were any systematic changes in the values obtained during the serial measurements, results were expressed for all subjects at each study as percentage deviations from the mean values (fig 1). There was no significant deviation from the mean values for any of the standard respiratory function tests. The standard deviation of the value for $\mathrm{FEV}_{1}$, however, was greater on the first studies.

\section{TWELVE-MINUTE DISTANCE}

The mean distance walked by all subjects was $900.6 \mathrm{~m}(\mathrm{SD} \pm 169 \cdot 3)$. Measurements of 12-minute distances for each subject are given in fig 2 and the mean values are listed in the table. The percentage differences from the means are shown in fig 1. In most subjects there were improvements between the results from assessment days 1 and 2 and days 2 and 3 ; the measurements on day 3 were significantly better $(\mathrm{P}<0.05$ by the paired $t$ test) than those on days 1 and 2. There was no significant change on comparison of the results obtained on day 3 with those on subsequent days. The coefficient of variation for all subjects on all days was $\pm 8.2 \%(1-20.6)$ but if the results from the first two assessments were excluded the coefficient of variation was reduced to $\pm 4 \cdot 2 \%(0 \cdot 8-$ 12.7).

\section{EXERCISE STUDIES}

Values of the changes in ventilation and heart rate corresponding to a change in oxygen uptake of $0.51 \mathrm{~min}^{-1}$ are listed in the table. The mean coefficients of variation, for all subjects, for the heart rate response was $\pm 19 \cdot 4 \%(13-26 \cdot 3)$ and for the ventilation response $\pm 16 \cdot 3 \%(6 \cdot 5-24)$.

Results of respiratory function tests, 12-minute walking test, and submaximal exercise tests from each subject. Values are of mean \pm one standard deviation. $V \mathrm{E} 0.5$ and $f H 0.5$ are changes in minute ventilation and heart rate corresponding to a change in oxygen uptake from 0.5 to $1.01 \mathrm{~min}^{-1}$

\begin{tabular}{|c|c|c|c|c|c|c|c|c|}
\hline Subject & $F E V_{1}(l)$ & $F V C(l)$ & $\begin{array}{l}\text { Transfer } \\
\text { factor } \\
\left(T_{L C O}\right) \\
(\mathrm{ml} / \mathrm{min} / \\
\mathrm{mmHg})^{*}\end{array}$ & $\begin{array}{l}T L C(l) \\
(\text { Helium } \\
\text { dilution) }\end{array}$ & $\begin{array}{l}\text { TLC }(l) \\
\text { (Body } \\
\text { plethys- } \\
\text { mograph) }\end{array}$ & $\begin{array}{l}\text { 12-minute } \\
\text { distance }(m)\end{array}$ & $\begin{array}{l}V_{E} 0.5 \\
(l / \mathrm{min})\end{array}$ & $\begin{array}{l}f H 0.5 \\
\text { (beats/ } \\
\text { min) }\end{array}$ \\
\hline $\begin{array}{r}1 \\
2 \\
3 \\
4 \\
5 \\
6 \\
7 \\
8 \\
9 \\
10 \\
11 \\
12 \\
13\end{array}$ & $\begin{array}{l}1 \cdot 0 \pm 0 \cdot 1 \\
1 \cdot 3 \pm 0 \cdot 2 \\
1 \cdot 2 \pm 0 \cdot 2 \\
1 \cdot 7 \pm 0 \cdot 2 \\
1 \cdot 5 \pm 0 \cdot 1 \\
1 \cdot 4 \pm 0 \cdot 3 \\
1 \cdot 4 \pm 0 \cdot 1 \\
2 \cdot 1 \pm 0 \cdot 2 \\
2 \cdot 1 \pm 0 \cdot 1 \\
1 \cdot 1 \pm 0 \cdot 1 \\
1 \cdot 0 \pm 0 \cdot 2 \\
1 \cdot 4 \pm 0 \cdot 7 \\
1 \cdot 9 \pm 0 \cdot 2\end{array}$ & $\begin{array}{l}2 \cdot 4 \pm 0 \cdot 2 \\
2 \cdot 8 \pm 0 \cdot 2 \\
2 \cdot 7 \pm 0 \cdot 3 \\
2 \cdot 7 \pm 0 \cdot 3 \\
2 \cdot 5 \pm 0 \cdot 2 \\
2 \cdot 8 \pm 0 \cdot 3 \\
2 \cdot 0 \pm 0 \cdot 2 \\
4 \cdot 3 \pm 0 \cdot 4 \\
2 \cdot 8 \pm 0 \cdot 4 \\
2 \cdot 3 \pm 0 \cdot 1 \\
2 \cdot 0 \pm 0 \cdot 3 \\
2 \cdot 7 \pm 0 \cdot 7 \\
2 \cdot 8 \pm 0 \cdot 3\end{array}$ & $\begin{array}{r}15 \cdot 7 \pm 1 \cdot 9 \\
5 \cdot 4 \pm 1 \cdot 2 \\
16 \cdot 2 \pm 4 \cdot 6 \\
12 \cdot 4 \pm 3 \cdot 0 \\
18 \cdot 6 \pm 1 \cdot 5 \\
15 \cdot 5 \pm 2 \cdot 0 \\
13 \cdot 5 \pm 1 \cdot 6 \\
16 \cdot 9 \pm 1 \cdot 5 \\
12 \cdot 4 \pm 0 \cdot 8 \\
14 \cdot 5 \pm 2 \cdot 6 \\
8 \cdot 9 \pm 1 \cdot 7 \\
17 \cdot 5 \pm 4 \cdot 8 \\
17 \cdot 2 \pm 1 \cdot 6\end{array}$ & $\begin{array}{l}5 \cdot 2 \pm 0 \cdot 4 \\
7 \cdot 4 \pm 0 \cdot 4 \\
6 \cdot 2 \pm 0 \cdot 4 \\
5 \cdot 4 \pm 0 \cdot 3 \\
4 \cdot 0 \pm 0 \cdot 4 \\
5 \cdot 0 \pm 0 \cdot 5 \\
4 \cdot 9 \pm 0 \cdot 4 \\
6 \cdot 8 \pm 0 \cdot 4 \\
4 \cdot 9 \pm 0 \cdot 3 \\
5 \cdot 0 \pm 0 \cdot 3 \\
5 \cdot 0 \pm 0 \cdot 2 \\
5 \cdot 2 \pm 1 \cdot 5 \\
6 \cdot 0 \pm 0 \cdot 6\end{array}$ & $\begin{array}{l}6 \cdot 4 \pm 0 \cdot 4 \\
8 \cdot 4 \pm 1 \cdot 7 \\
7 \cdot 1 \pm 0 \cdot 2 \\
6 \cdot 8 \pm 0 \cdot 4 \\
5 \cdot 7 \pm 0 \cdot 8 \\
7 \cdot 5 \pm 0 \cdot 9 \\
6 \cdot 6 \pm 0 \cdot 5 \\
7 \cdot 7 \pm 0 \cdot 3 \\
6 \cdot 7 \pm 0 \cdot 8 \\
6 \cdot 9 \pm 0 \cdot 3 \\
6 \cdot 2 \pm 0 \cdot 1 \\
8 \cdot 0 \pm 0 \cdot 7 \\
7 \cdot 2 \pm 0 \cdot 6\end{array}$ & $\begin{array}{r}1145 \cdot 1 \pm 43 \cdot 4 \\
821 \cdot 1 \pm \quad 8 \cdot 8 \\
971 \cdot 2 \pm 16 \cdot 0 \\
853 \cdot 2 \pm 6 \cdot 5 \\
1048 \cdot 7 \pm 54 \cdot 0 \\
842 \cdot 8 \pm 156 \cdot 9 \\
787 \cdot 7 \pm 32 \cdot 2 \\
916 \cdot 2 \pm 55 \cdot 6 \\
830 \cdot 2 \pm 120 \cdot 4 \\
1009 \cdot 0 \pm 56 \cdot 0 \\
532 \cdot 4 \pm 31 \cdot 6 \\
963 \cdot 6 \pm 99 \cdot 8 \\
986 \cdot 8 \pm 202 \cdot 9\end{array}$ & $\begin{array}{r}11 \cdot 4 \pm 2 \cdot 3 \\
9 \cdot 8 \pm 1 \cdot 2 \\
12 \cdot 8 \pm 2 \cdot 0 \\
15 \cdot 8 \pm 2 \cdot 9 \\
12 \cdot 1 \pm 2 \cdot 9 \\
10 \cdot 0 \pm 1 \cdot 7 \\
15 \cdot 3 \pm 2 \cdot 6 \\
12 \cdot 4 \pm 0 \cdot 8 \\
13 \cdot 9 \pm 2 \cdot 4 \\
9 \cdot 8 \pm 1 \cdot 4 \\
20 \cdot 6 \pm 3 \cdot 4 \\
12 \cdot 5 \pm 2 \cdot 0 \\
14 \cdot 8 \pm 2 \cdot 5\end{array}$ & $\begin{array}{l}13 \cdot 0 \pm 3 \cdot 6 \\
15 \cdot 0 \pm 1 \cdot 6 \\
16 \cdot 9 \pm 3 \cdot 8 \\
20 \cdot 0 \pm 3 \cdot 6 \\
24 \cdot 6 \pm 6 \cdot 0 \\
22 \cdot 1 \pm 4 \cdot 2 \\
15 \cdot 6 \pm 2 \cdot 4 \\
18 \cdot 5 \pm 1 \cdot 8 \\
25 \cdot 9 \pm 4 \cdot 1 \\
22 \cdot 4 \pm 3 \cdot 3 \\
19 \cdot 6 \pm 6 \cdot 3 \\
26 \cdot 3 \pm 5 \cdot 6 \\
19 \cdot 2 \pm 4 \cdot 1\end{array}$ \\
\hline
\end{tabular}

*2.986 $\times \mathrm{mmol} \mathrm{min}^{-1} \mathrm{kPa}^{-1}$. 


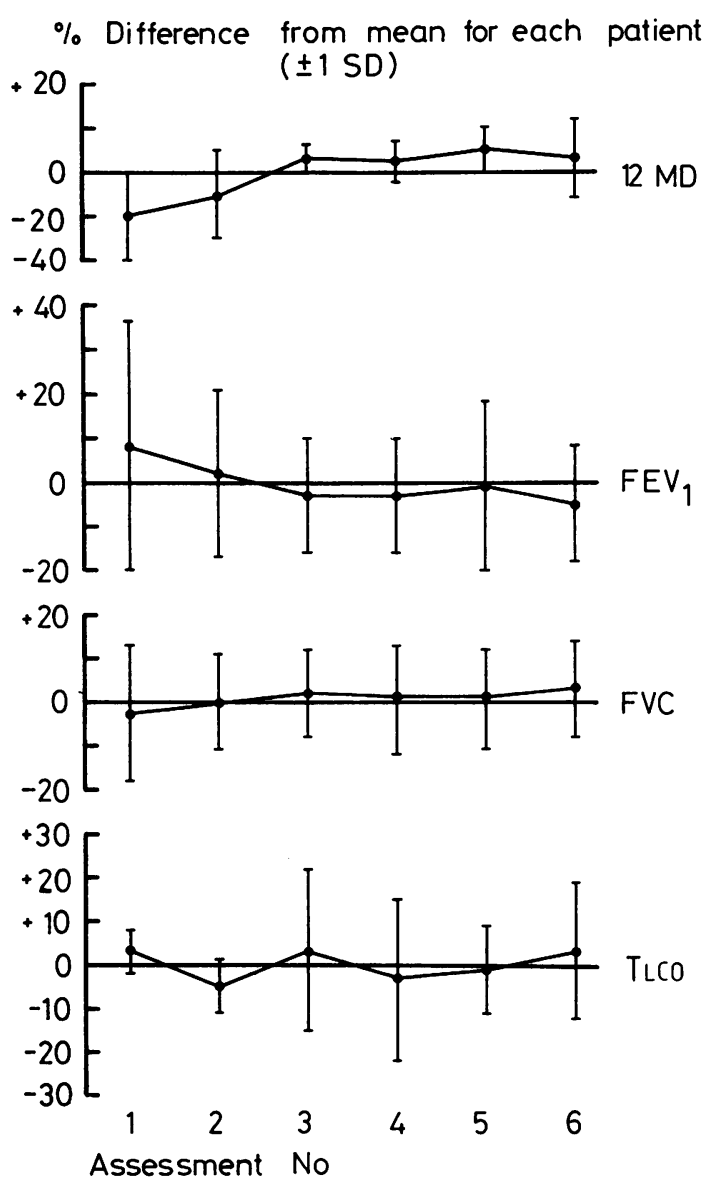

Fig 1 Average differences ( \pm one $S D$ ) at each assessment from means of all assessments of 12-minute distance, $F E V_{1}, F V C$, and transfer factor. Note systemic and random errors of first two assessments of 12-minute distance and large random error of first assessments of FEV 1 .

CORRELATIONS OF RESULTS OF 12-MINUTE WALKING TEST AND RESULTS OF STANDARD RESPIRATORY FUNCTION TESTS

There was a significant correlation between subjects of the results of the 12-minute distance with TLCO $(r=0.67, P<0.01)$ but not with any other tests of lung function. There was a significant inverse correlation of 12-minute distance with the ventilatory response $(r=0.77, P<0.01)$ but not with the heart rate response to an increase in oxygen uptake of $0.51 \mathrm{~min}^{-1}$.

\section{Discussion}

The results in the present paper emphasise the

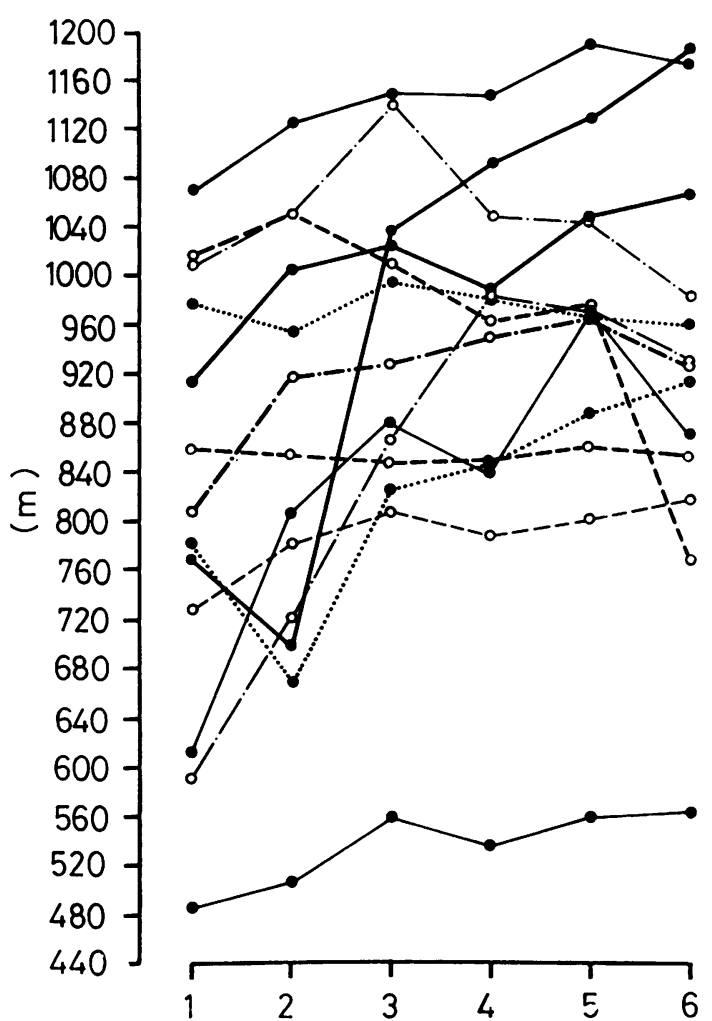

Fig 2 Twelve-minute walking distances. Results are shown from 13 subjects studied on six occasions.

considerable variation in the results of respiratory function tests in patients with chronic obstructive airways disease. Several factors may contribute to causing the variation. In measuring transfer factor there are various technical difficulties that have been listed by Cotes (1963). Errors in making 윽 spirometric measurements should be less than $2 \%$ (Cotes, 1975). There is also a cyclical variation in lung function probably related to sleep, meals, day- N light hours, and time of year. This cyclical vari- or ation is only small, however-for instance, the fall $\tilde{O}$ in TLCo between morning and afternoon is only $\underset{\omega}{\mathbb{N}}$ $1.2 \%$ an hour, and the amplitude of the cyclical 0 variation in $\mathrm{FEV}_{1}$ due to time of year is only 0 about $0 \cdot 11$ (Cotes, 1975). The effects of diurnal $\overparen{\varnothing}$ variation would be minimal in our subjects be- $\stackrel{\oplus}{+}$ cause measurements were always made at the same time of the day.

Values of the coefficients of variation for the $\stackrel{\mathbb{D}}{\stackrel{D}{\circ}}$ heart rate and ventilatory responses to an increase $\mathbb{Q}$ in oxygen uptake of $0.51 \mathrm{~min}^{-1}$ obtained from our $\overline{0}$ subjects are similar to the values obtained by Cotes (1972) from normal subjects. Davies et al 응 
(1970) reported that, after repeated tests in normal subjects, there was a significant decrease in heart rate and minute ventilation at a standard oxygen uptake. This change, which was attributed to a training effect, was not seen in our patients, probably because of the short duration of the tests and the long intervals between assessments. The reason for the variations in the results from our subjects is not clear. All subjects were in steady clinical states with one exception, subject 12 , who attended on the final day despite an exacerbation of his chronic bronchitis, and on this occasion there was a deterioration in the results of his standard respiratory function tests, exercise studies, and 12-minute walking test. As he had felt himself sufficiently fit to attend, in accordance with the protocol of the trial, his results have been included.

Fletcher (1964) reported large spontaneous variations in $\mathrm{FEV}_{1}$ in normal subjects. He found that in 173 normal men $5 \%$ had a difference in $\mathrm{FEV}_{1}$ of 0.41 or more between two readings at $10-12$ days' interval. The variation was greater in subjects with abnormal test results. In the present study, measurements were made on six occasions to determine whether reproducibility improved with repetition. Figure 1 shows that for FVC and Tuco the percentage difference from the mean did not decrease with repeated assessments nor was there a decrease in standard deviation-that is, the variation was of a similar order for the later assessments as for the early ones. No significant change was obtained in the values for TLC, or the values of heart rate and ventilatory responses to exercise. For $\mathrm{FEV}_{1}$ the standard deviation was greater on day 1 than on subsequent assessments.

The results obtained for the 12-minute walking test show that there was a significant improvement over the first three assessments and the coefficients of variation decreased. If the results of the first two tests were ignored the mean coefficient of variation was reduced to only $\pm 4.2 \%$, a value that is smaller than for any of the other assessments made. These results do indicate, however, that at least three assessments are necessary to obtain reproducible values.

Recently, submaximal rather than maximal exercise testing has been advocated as a satisfactory method of evaluating cardiorespiratory fitness (Spiro et al, 1975; Kappagoda et al, 1977). We undertook submaximal exercise testing in all our patients at each attendance and showed a significant inverse correlation between the ventilatory response to an increase in oxygen uptake of $0.51 \mathrm{~min}^{-1}$ and the 12-minute distance. McGavin et al (1976) using maximal exercise testing also found a correlation between 12-minute distance and both maximal oxygen uptake and maximal minute ventilation, though their correlations were less close $(r=0.52$ and 0.53 respectively, $P<0.01)$. They recognised that the 12-minute walk did not stress subjects to the same limits as a maximal exercise test on a treadmill or bicycle ergometer. Recently Reed et al (1977) using submaximal exercise tests in patients with emphysema have reported that the rate of increase in minute ventilation shows a close correlation with the transfer factor but not with $\mathrm{FEV}_{1}$. We also found that the ventilatory response to exercise correlated with the transfer factor $(r=0.59)$ and that both these indices correlated with the results of the 12-minute distance. $\mathrm{FEV}_{1}$ failed to correlate with either 12minute distance or the ventilatory response to exercise. This would support the view that, in submaximal exercise tests including the 12-minute walk, performance is determined more by gas exchange capacity than by airways obstruction.

It is important to obtain objective measures of disability in patients with chronic obstructive airways disease as evidence from both cardiac patients (Patterson et al, 1972) and respiratory patients (Fletcher, 1964) suggests that the correlation between clinical estimate of function and objective indices (such as exercise testing) is poor and decreases with the severity of the patient's condition. Other simple self-paced exercise tests, such as measurement of work rate in chronic bronchitics during stair climbing (Johnson et al, 1977) and measurement of heart rate at a standard walking speed in geriatric patients (Bassey et al, 1976) have also recently been described. These tests and the 12-minute walk are straightforward, cheap, and safe, and correspond more closely to the demands of everyday activities than exercise testing on a treadmill or bicycle ergometer.

In summary we found considerable variations of both standard respiratory function tests and of submaximal exercise tests. This spontaneous variability should be taken into account when assessing the possible value of treatment. The 12-minute walking test was found to be a useful measure of disability in patients with chronic obstructive airways disease and, if the first two assessments are ignored, it provides more reproducible results than those obtained by any of the other tests investigated.

We thank Mrs R A Bunting and Mrs A Siddall for their expert technical help.

\section{References}

Bassey, E J, Fentem, P H, MacDonald, I C, and 
Scriven, P M (1976). Self-paced walking as a method for exercise testing in elderly and young men. Clinical Science and Molecular Medicine, 51, 609612.

Bates, D V, Macklem, P T, and Christie, R V (1971). Respiratory Function in Disease, 2nd edition. Saunders, Philadelphia.

Cotes, J E (1963). Effect of variability in gas analysis on the reproducibility of the pulmonary diffusing capacity by the single breath method. Thorax, 18, 151-154.

Cotes, J E (1972). Response to progressive exercise: a three-index test. British Journal of Diseases of the Chest, 66, 169-184.

Cotes, J E (1975). Lung Function, 3rd edition, pp 101 and 361-2. Blackwell, Oxford.

Davies, C T M, Tuxworth, W, and Young, J M (1970). Physiological effects of repeated exercise. Clinical Science, 39, 247-258.

Fletcher, C M (1964). The problem of observer variation in medical diagnosis with special reference to chest diseases. Methods of Information in Medicine, 3, 98-103.

Johnson, A N, Cooper, D F, and Edwards, R H T (1977). Exertion of stair-climbing in normal subjects and in patients with chronic obstructive bronchitis. Thorax, 32, 711-716.

Kappagoda, C T, Linden, R J, and Newell, J P (1977). Validation of a submaximal exercise test. Journal of Physiology, 268, 19P-20P.
Laws, J W, and Heard, B E (1962). Emphysema and $\overrightarrow{\bar{F}}$ the chest film: a retrospective radiological and 0 pathological study. British Journal of Radiology, $35,750-761$.

McGavin, C R, Gupta, S P, and McHardy, G J R $\frac{0}{\vec{D}}$ (1976). Twelve-minute walking test for assessing $\bigcirc$ disability in chronic bronchitis. British Medical @ै Journal, 1, 822-823.

Medical Research Council Working Party (1965). Report. Definition and classification of chronic $\vec{\omega}$ bronchitis. Lancet, 1, 775-779.

Patterson, J A, Naughton, J, Pietras, R J, and Gunnar, R M (1972). Treadmill exercise in assessment of $x$ functional capacity of patients with cardiac disease. $\stackrel{\omega}{A}$ American Journal of Cardiology, 30, 757-762.

Reed, J W, Dowd, D E, and Hutchinson, D C S N (1977). Relationships between indices of exercise $A$ performance and resting lung function in patients 을 with radiological emphysema. Clinical Science and Molecular Medicine, 53, 2P-3P.

Spiro, S G, Hahn, H L, Edwards, R H T, and Pride, N B (1975). An analysis of the physiological strain of submaximal exercise in patients with chronic obstructive bronchitis. Thorax, 30, 415-425.

Requests for reprints to: Dr R Hainsworth, Depart-ō ment of Cardiovascular Studies, University of Leeds, Leeds LS2 9JT. 